\title{
Candesartan effect on inflammation in hypertension
}

\author{
Giuseppe Derosa ${ }^{1}$, Pamela Maffioli ${ }^{1}$, Sibilla AT Salvadeo ${ }^{1}$, Ilaria Ferrari ${ }^{1}$, Alessia Gravina ${ }^{1}$, Roberto Mereu ${ }^{1}$, \\ Ilaria Palumbo ${ }^{1}$, Angela D’Angelo ${ }^{1}$ and Arrigo FG Cicero ${ }^{2}$
}

The aim of this study was to evaluate the effect of candesartan on inflammatory biomarkers in hypertensive patients with and without type 2 diabetes mellitus after a standardized oral fat load (OFL). A total of 219 patients were enrolled: 106 patients were assigned to the non-diabetic hypertensive $(\mathrm{NH})$ group, and 113 to the diabetic hypertensive (DH) group. All patients received candesartan therapy for 6 months and underwent a standardized OFL at baseline and after 6 months of therapy. We evaluated systolic blood pressure (SBP) and diastolic blood pressure (DBP), blood glucose (BG), triglycerides (Tg), soluble intercellular adhesion molecule-1 (sICAM-1), interleukin-6 (IL-6) and high-sensitivity C reactive protein (Hs-CRP). At baseline, glycated hemoglobin, homeostasis model assessment insulin resistance index, BG, fasting plasma insulin, Tg, sICAM-1, IL-6 and Hs-CRP in the DH group were significantly higher, whereas high-density lipoprotein-cholesterol value was significantly lower compared to NH group. After 6 months of candesartan therapy, sICAM-1, IL-6 and Hs-CRP were significantly lower compared to baseline in both groups; furthermore, there was a significant decrease of SBP and DBP values in both groups. After the OFL administered at baseline, there was an increase of Tg, sICAM-1, IL- 6 and Hs-CRP in both groups. After the OFL administered after 6 months of therapy, instead, there was no significant variation of BG, Tg or sICAM-1 value in both groups, whereas there was an increase of IL- 6 and Hs-CRP compared to time 0 . We observed that candesartan treatment attenuated the inflammatory answer in both groups of patients, even if more efficiently in nondiabetic ones.

Hypertension Research (2010) 33, 209-213; doi:10.1038/hr.2009.212; published online 15 January 2010

Keywords: candesartan; inflammation; oral fat load; type 2 diabetes mellitus

\section{INTRODUCTION}

Inflammatory processes are largely involved in atherosclerosis development, ${ }^{1}$ and they are strongly linked with the cardiovascular disease risk associated to some common conditions as hypertension and insulin resistance. ${ }^{2}$

Angiotensin II may be to a large degree responsible for triggering vascular inflammation by inducing oxidative stress, resulting in upregulation of inflammatory mediators. ${ }^{3}$ This phenomenon appears to be particularly evident in patients affected by insulin resistance and its clinical manifestations such as metabolic syndrome and type 2 diabetes mellitus. ${ }^{4}$ On the other side, there is increasing evidence that the pharmacological block of angiotensin II receptors leads to an improvement of different inflammatory biomarkers in hypertensive patients, ${ }^{5}$ even when associated to metabolic syndrome ${ }^{6}$ or with type 2 diabetes mellitus, ${ }^{7}$ and this effect could at least partly explain the antiatherosclerotic effect of sartans. ${ }^{8}$

Postprandial hyperlipidemia is a continuous pro-inflammatory stimulus for the vascular wall, partly modulated by the peroxisome proliferator-actived receptor $\alpha$ activation. ${ }^{9}$

The aim of our study is to evaluate the effect of an angiotensin receptor blocker with mild peroxisome proliferator-actived receptor$\alpha$-activating action on inflammatory biomarkers in hypertensive patients with and without type 2 diabetes mellitus after a standardized oral fat load (OFL).

\section{METHODS}

Study design and patients

This multicenter trial was conducted in the Internal Medicine and Therapeutics Department at University of Pavia, and in the 'G. Descovich' Atherosclerosis Study Center, Internal medicine, Aging and Kidney disease Department at University of Bologna.

We enrolled 219 Caucasian (112 men and 107 women), aged $\geqslant 18$ of either sex, hypertensive (non-diabetic hypertensive, NH; defined as sitting systolic blood pressure (SBP) $>130$ and $<180 \mathrm{~mm} \mathrm{Hg}$ and sitting diastolic blood pressure (DBP) $>80$ and $<100 \mathrm{~mm} \mathrm{Hg}$ ), outpatients; of these, 113 patients were type 2 diabetics (diabetic hypertensive, DH; according to the American Diabetes Association criteria ${ }^{10}$ and were required to have been diagnosed as being diabetic for at least 6 months.

Patients with secondary hypertension, history of ketoacidosis or with unstable or rapidly progressive diabetic retinopathy, nephropathy or neuropathy were excluded, as were patients with impaired liver function (defined as plasma aminotransferase (aspartate aminotransferase (normal values: 11$39 \mathrm{mU} \mathrm{ml}^{-1}$ ), and alanine aminotransferase (normal values: $11-34 \mathrm{mU} \mathrm{ml}^{-1}$ )) and/or $\gamma$-glutamyltransferase (normal values: $11-53 \mathrm{mU} \mathrm{ml}^{-1}$ ), impaired kidney function (defined as serum creatinine level (normal values: $0.6-1.3 \mathrm{mg}$ per

\footnotetext{
${ }^{1}$ Department of Internal Medicine and Therapeutics, University of Pavia, Fondazione IRCCS Policlinico S. Matteo, Pavia, Italy and ${ }^{2 ‘} \mathrm{D}$. Campanacci' Clinical Medicine and Applied Biotechnology Department, 'G. Descovich' Atherosclerosis Study Center, University of Bologna, Bologna, Italy

Correspondence: Professor G Derosa, Department of Internal Medicine and Therapeutics, University of Pavia, Fondazione IRCCS Policlinico S. Matteo, Pavia, P.le C. Golgi, 2, Pavia 27100, Italy.

E-mail: giuseppe.derosa@unipv.it

Received 13 October 2009; revised 3 November 2009; accepted 9 November 2009; published online 15 January 2010
} 
$100 \mathrm{ml}$ )) or anemia. Patients with unstable cardiovascular conditions (for example, New York Heart Association class I-IV congestive heart failure or a history of myocardial infarction or stroke) or cerebrovascular conditions within 6 months of study enrollment were also excluded. Women who were pregnant, lactating or of childbearing potential while not taking adequate contraceptive precautions were also excluded. Patients with known contraindications or intolerance to sartans were also not included in the study.

All patients were taking different antihypertensive drugs (30 subjects (13.70\%) ACE-inhibitors (17 ramipril (56.67\%), 7 perindopril (23.33), 6 enalapril (20.00)); 39 subjects (17.80\%) angiotensin II receptor blockers (11 losartan (28.21\%), 12 valsartan (30.77\%), 8 irbesartan (20.51\%), 8 telmisartan $(20.51 \%))$; 32 subjects (14.61\%) calcium antagonists (32 amlodipine (100\%)); 27 subjects $(12.33 \%)$ diuretics (27 hydrochlorothiazide (100\%)); 16 subjects (7.30\%) $\beta$-blockers (10 metoprolol (62.5\%), 6 carvedilol (37.5\%)); 12 subjects $(5.48 \%) \alpha$-blockers (12 doxazosin (100\%))) in monotherapy or in combination therapy.

At the beginning of the study, they stopped their antihypertensive therapy and they took candesartan, $32 \mathrm{mg}$ per day for 6 months. At the beginning and at the end of the study (after candesartan therapy), they underwent also an OFL.

Participants comprised 112 men (51.1\%) and 107 women (48.9\%). There were no significant differences between centers in sex distribution, age and in hypertension duration.

At entry, type 2 diabetic patients were taking oral hypoglycemic agents (41 (36.28\%) patients, sulfonylureas (14 (34.14\%) glibenclamide, 19 (46.34\%) glimepiride and $8(19.51 \%)$ gliclazide); $53(46.90 \%)$ patients, biguanide (53 (100\%) metformin); $30(26.55 \%)$ patients, metiglinide derivatives (18 (60.00\%) repaglinide and $12(40.00 \%)$ nateglinide); $82(72.57 \%)$ patients, thiazolidinediones (48 $(58.54 \%)$ pioglitazone and $34(41.46 \%)$ rosiglitazone) and $21(18.58 \%)$ patients, $\alpha$-glucosidase inhibitor (21 (100\%) acarbose)) in monotherapy or in combination therapy. One hundred and twenty-one patients were taking lipid-lowering drugs, and 146 patients were taking antiaggregation drugs. No change in diet intake or in physical activity throughout the study was recommended.

Suitable subjects, identified from review of case notes and/or computerized clinic registers, were contacted personally or by telephone.

The study protocol was approved at each site by institutional review boards and was conducted in accordance with the Declaration of Helsinki Principles. All patients provided written informed consent.

\section{Laboratory methods}

Before starting the study, all patients underwent a measurement of body mass index, glycated hemoglobin, blood glucose (BG), fasting plasma insulin (FPI), homeostasis model assessment insulin resistance index (HOMA-IR), lipid profile (total cholesterol, low-density lipoprotein-cholesterol, high-density lipoprotein-cholesterol and triglycerides (Tg)), SBP, DBP, soluble intercellular adhesion molecule-1 (sICAM-1), interleukin-6 (IL-6) and high-sensitivity C reactive protein (Hs-CRP).

Venous blood samples were taken for all patients at $12 \mathrm{~h}$ overnight fasting state between 0800 and 0900 hours and were drawn into precooled sterile tubes from an indwelling catheter inserted into an antecubital vein and put into a vacutainer system (Becton Dickinson, Meylan Cedex, France) without venous stasis.

We used plasma obtained by addition of $\mathrm{Na}_{2}$-EDTA $\left(1 \mathrm{mg} \mathrm{ml}^{-1}\right)$ separated from red blood cells by centrifugation at $3000 \mathrm{~g}$ for $15 \mathrm{~min}$ at $4{ }^{\circ} \mathrm{C}$, immediately then transferred into sterile cryovials (Greiner Labortechnik, Nürtringen, Germany) in aliquots of $1 \mathrm{ml}$ and froze and stored at $-80^{\circ} \mathrm{C}$ for no more than 3 months. All measurements were performed in a central laboratory.

Body mass index was calculated by the investigators as weight in kilograms divided by the square of height in meters. The estimate of insulin resistance was calculated by HOMA-IR with the formula: FPI $\left(\mu \mathrm{U} \mathrm{ml}^{-1}\right) \times \mathrm{FPG}\left(\mathrm{mmoll}^{-1}\right) /$ 22.5, as described by Matthews et al. ${ }^{11}$

Blood pressure measurements were obtained from each patient (using the right arm) in the seated position, using a standard mercury sphygmomanometer (Erkameter 3000; ERKA, Bad Tolz, Germany) (Korotkoff I and V) with a cuff of appropriate size. Blood pressure was measured by the same investigator at each visit, in the morning, after the patient had rested for $\geqslant 10 \mathrm{~min}$ in a quiet room. Three successive blood pressure readings were obtained at $1 \mathrm{~min}$ intervals, and the mean of the three readings was calculated.

BG was assayed by glucose-oxidase method (GOD/PAP; Roche Diagnostics, Mannheim, Germany) with intra- and interassay coefficients of variation (CsV) of $<2 \%{ }^{12}$

Plasma insulin was assayed with Phadiaseph Insulin RIA (Pharmacia, Uppsala, Sweden) by using a second antibody to separate the free and antibody-bound 125 I-insulin (intra- and interassay CsV: 4.6 and 7.3\%, respectively). ${ }^{13}$

Total cholesterol and $\mathrm{Tg}$ levels were determined using fully enzymatic techniques ${ }^{14,15}$ on a clinical chemistry analyzer (HITACHI 737; Hitachi, Tokyo, Japan); intra- and interassay CsV were 1.0 and $2.1 \%$ for total cholesterol measurement, and 0.9 and $2.4 \%$ for $\mathrm{Tg}$ measurement, respectively. Highdensity lipoprotein-cholesterol level was measured after precipitation of plasma apo B-containing lipoproteins with phosphotungstic acid ${ }^{16}$ intra- and interassay $\mathrm{CsV}$ were 1.0 and $1.9 \%$, respectively; low-density lipoprotein-cholesterol level was calculated by the Friedewald formula. ${ }^{17}$

IL-6 was determined using commercially available enzyme-linked immunosorbent assay kits (R\&D Systems, Minneapolis, MN, USA) according to manufacturer's instructions. The intra- and interassay $\mathrm{CsV}$ were 4.9 and $7.1 \%$, respectively. ${ }^{18}$

Hs-CRP was measured with use of latex-enhanced immunonephelometric assays on a BN II analyzer (Dade Behring, Newark, DE, USA). The intra- and interassay $\mathrm{CsV}$ were 5.7 and $1.3 \%$, respectively. ${ }^{19}$

sICAM-1 was assessed using commercially available enzyme-linked immunosorbent assay kits (R\&D Systems) according to manufacturers instructions. The intra- and interassay $\mathrm{CsV}$ were $<10 \%$, respectively. ${ }^{20}$

Body mass index, glycated hemoglobin, BG, FPI, HOMA-IR, SBP, DBP, lipid profile, sICAM-1, IL-6 and Hs-CRP were evaluated at baseline, whereas BG, Tg, sICAM-1, IL-6 and Hs-CRP were evaluated before and after OFL and at the end of the 6 months of candesartan therapy. To evaluate the tolerability assessments, we recorded all adverse events.

\section{OFL test}

The fat load was given between 0800 and 0900 hours after a 12-h fast and a 3-day abstention from alcohol intake. Participants were also asked to refrain from heavy exercise during the preceding days. The test drink consisted of $350 \mathrm{ml}$ whipping cream ( $35 \%$ fat), two tablespoons of chocolate-flavored syrup, one tablespoon of granulated sugar and one tablespoon of instant nonfat dry milk. This volume contained $1147 \mathrm{kcal}$, of which $12 \%$ were from protein, $20 \%$ from carbohydrate and $68 \%$ from fat. It had $472 \mathrm{mg}$ cholesterol and a polyunsatu$\mathrm{rated} / \mathrm{saturated} \mathrm{ratio} \mathrm{of} 0.06$. A weight-adjusted meal ( $1 \mathrm{~g}$ fat per $\mathrm{kg}$ body weight) was served to approximately $400 \mathrm{ml}$ of the mixture. The fat load mixture was consumed within $10 \mathrm{~min}$. After the ingestion of the fat load, subjects were only allowed to drink water during the following $12 \mathrm{~h}$. Blood samples were drawn before and 3, 6, 9 and $12 \mathrm{~h}$ after the fat load. Subjects were required to sit in the hospital hall: only standard walk in the hospital perimeter was accepted.

\section{Statistical analysis}

Non-parametric tests were used in the statistical analysis of the data because data were not normally distributed (Kolmogorov-Smirnov test). Outcome variables with a skewed distribution were transformed to a log scale before statistical testing. A two-way repeated measures analysis of variance was performed to assess overall differences in postprandial responses. The Bonferroni correction for multiple comparisons was carried out. ${ }^{21}$ The incremental area under the curve was calculated as the increased response above baseline minus any drop below baseline, based on the trapezoid rule. ${ }^{22}$ Differences over time and association between BG and $\mathrm{Tg}$ levels with other variables were evaluated with stepwise multiple linear regression analysis. A $P$-value of less than 0.05 was considered statistically significant. All tests were two-sided. Statistical 6.0 (Statsoft, Tulsa, OK, USA) was used for statistical computations. All results are expressed as means \pm standard deviation.

\section{RESULTS}

\section{Study sample at baseline}

A total of 219 patients (112 men and 107 women) were enrolled in the study. At baseline glycated hemoglobin, HOMA-IR, BG, FPI, Tg, 
Table 1 Patients characteristics at baseline in $\mathrm{NH}$ and $\mathrm{DH}$ group

\begin{tabular}{|c|c|c|}
\hline & $\mathrm{NH}$ & $D H$ \\
\hline$n$ & 106 & 113 \\
\hline $\operatorname{Sex}(M / F)$ & $54 / 52$ & $58 / 55$ \\
\hline Age (years) & $57 \pm 8$ & $59 \pm 10$ \\
\hline Hypertension duration (years) & $6 \pm 3$ & $5 \pm 2$ \\
\hline Diabetes duration (years) & - & $7 \pm 3$ \\
\hline Height (m) & $1.69 \pm 0.05$ & $1.68 \pm 0.04$ \\
\hline Weight (kg) & $76.8 \pm 7.6$ & $76.5 \pm 7.2$ \\
\hline BMI $\left(\mathrm{kg} \mathrm{m}^{-2}\right)$ & $26.9 \pm 1.2$ & $27.1 \pm 1.3$ \\
\hline $\mathrm{HbA}_{1 \mathrm{c}}(\%)$ & $5.2 \pm 0.3$ & $7.4 \pm 0.8^{* *}$ \\
\hline $\mathrm{BG}(\mathrm{mg}$ per $100 \mathrm{ml})$ & $90.6 \pm 7.2$ & $136.2 \pm 10.5^{*}$ \\
\hline $\mathrm{FPI}\left(\mu \mathrm{U} \mathrm{ml}^{-1}\right)$ & $8.7 \pm 2.7$ & $20.2 \pm 5.8^{*}$ \\
\hline HOMA index & $1.96 \pm 0.34$ & $6.85 \pm 1.82^{* *}$ \\
\hline $\mathrm{SBP}(\mathrm{mm} \mathrm{Hg})$ & $145.8 \pm 6.9$ & $143.6 \pm 6.5$ \\
\hline DBP (mm Hg) & $96.3 \pm 4.6$ & $94.7 \pm 4.1$ \\
\hline TC (mg per $100 \mathrm{ml}$ ) & $195.4 \pm 16.2$ & $191.2 \pm 15.4$ \\
\hline LDL-C (mg per $100 \mathrm{ml}$ ) & $127.1 \pm 10.2$ & $122.1 \pm 9.1$ \\
\hline HDL-C (mg per $100 \mathrm{ml}$ ) & $49.3 \pm 7.5$ & $39.7 \pm 3.8^{*}$ \\
\hline Tg (mg per $100 \mathrm{ml}$ ) & $94.8 \pm 21.6$ & $146.9 \pm 39.7^{*}$ \\
\hline sICAM-1 (ng ml-1) & $163.4 \pm 28.3$ & $278.2 \pm 35.6^{*}$ \\
\hline IL-6 $\left(\mathrm{pg} \mathrm{mI}^{-1}\right)$ & $1.9 \pm 0.8$ & $3.3 \pm 1.2^{* *}$ \\
\hline Hs-CRP (mg $\left.\left.\right|^{-1}\right)$ & $1.2 \pm 0.3$ & $2.4 \pm 1.2^{*}$ \\
\hline \multicolumn{3}{|c|}{$\begin{array}{l}\text { Abbreviations: BG, blood glucose; BMI, body mass index; DBP, diastolic blood pressure; FPI, } \\
\text { fasting plasma insulin; HbA } 11 \text {, glycated hemoglobin; HDL-C, high-density lipoprotein- } \\
\text { cholesterol; HOMA index, homeostasis model assessment index; Hs-CRP, high-sensitivity C } \\
\text { reactive protein; IL-6, interleukin-6; LDL-C, low-density lipoprotein-cholesterol; SBP, systolic } \\
\text { blood pressure; sICAM-1, soluble intercellular adhesion molecule-1; TC, total cholesterol; Tg, } \\
\text { triglycerides. } \\
\text { Data are means } \pm \text { s.d. } \\
{ }^{*} P<0.05 \text { vs. NH; }{ }^{* *} P<0.01 \text { vs. NH. }\end{array}$} \\
\hline
\end{tabular}

Table 2 Baseline values in NH and DH patients and after 6 months of candesartan therapy

\begin{tabular}{lcccc}
\hline & Baseline NH & 6 months & Baseline DH & 6 months \\
\hline BG (mg per 100 ml) & $90.6 \pm 7.2$ & $87.9 \pm 6.4$ & $136.2 \pm 10.5^{*} 131.3 \pm 9.7^{*, \leftarrow}$ \\
Tg (mg per $100 \mathrm{ml})$ & $94.8 \pm 21.6$ & $87.8 \pm 19.8$ & $146.9 \pm 39.7^{*}$ & $130.4 \pm 33.5^{*, \pm}$ \\
sICAM-1 $\left(\mathrm{ng} \mathrm{ml}^{-1}\right)$ & $163.4 \pm 28.3$ & $139.5 \pm 20.1^{*}$ & $278.2 \pm 35.6^{*}$ & $231.8 \pm 30.8^{*, \wedge, \circ}$ \\
IL-6 $\left(\mathrm{pg} \mathrm{ml}^{-1}\right)$ & $1.9 \pm 0.8$ & $1.3 \pm 0.5^{*}$ & $3.3 \pm 1.2^{* *}$ & $2.2 \pm 1.1^{*, \wedge, \circ}$ \\
Hs-CRP $\left(\mathrm{mgl}^{-1}\right)$ & $1.2 \pm 0.3$ & $0.8 \pm 0.2^{*}$ & $2.4 \pm 1.2^{*}$ & $1.8 \pm 0.9^{*, \wedge, \circ}$ \\
\hline
\end{tabular}

Abbreviations: BG, blood glucose; Hs-CRP, high-sensitivity $\mathrm{C}$ reactive protein; IL-6, interleukin6; sICAM-1, soluble intercellular adhesion molecule-1; Tg, triglycerides.

Data are means \pm s.d.

${ }^{\star} P<0.05$ vs. baseline $\mathrm{NH} ;{ }^{*} P<0.01$ vs. baseline $\mathrm{NH} ; \wedge P<0.05$ vs. baseline $\mathrm{DH} ;{ }^{£} P<0.05$

vs. 6 -month $\mathrm{NH} ;{ }^{\circ} \mathrm{P}<0.01$ vs. 6 -month $\mathrm{NH}$.

sICAM-1, IL-6 and Hs-CRP values were significantly higher in DH group compared to $\mathrm{NH}$ group, whereas high-density lipoproteincholesterol value was significantly lower (Tables 1 and 2).

\section{Study sample after the first OFL}

After OFL, there was no significant variation of BG, whereas there was a significant increase of Tg value at time 6 in both groups compared to time $0 ; \mathrm{BG}$, and $\mathrm{Tg}$ values observed at time 0 in $\mathrm{DH}$ group were significantly higher than in $\mathrm{NH}$ group. Furthermore, BG and Tg values obtained at time 6 in $\mathrm{DH}$ group were significantly higher than the values obtained in $\mathrm{NH}$ group at time 0 and 6 . Regarding inflammatory parameters, sICAM-1, IL-6 and Hs-CRP values were significantly increased in both groups at time 6 compared to time 0. Comparing the two groups, sICAM-1, IL-6 and Hs-CRP values were significantly higher in DH group at time 0 than the values obtained in $\mathrm{NH}$ group at the same time. At time 6 in DH group, sICAM-1, IL-6 and Hs-CRP values were significantly higher than those obtained in NH group at time 06 (Tables 3 and 5).
Table 3 Time 0 and after $6 \mathrm{~h}$ during OFL at baseline in $\mathrm{NH}$ and $\mathrm{DH}$ patients

\begin{tabular}{|c|c|c|c|c|}
\hline & Time $\mathrm{OhNH}$ & Time $6 \mathrm{~h} \mathrm{NH}$ & Time $O \mathrm{~h} \mathrm{DH}$ & Time $6 \mathrm{~h} \mathrm{DH}$ \\
\hline $\mathrm{BG}(\mathrm{mg}$ per $100 \mathrm{ml})$ & $90.6 \pm 7.2$ & $93.4 \pm 7.8$ & $136.2 \pm 10.5^{*}$ & $142.6 \pm 11.3^{*, \circ}$ \\
\hline Tg (mg per $100 \mathrm{ml}$ ) & $94.8 \pm 21.6$ & $142.8 \pm 35.4^{*}$ & $146.9 \pm 39.7^{*}$ & $172.8 \pm 54.6^{\S, \wedge, \circ}$ \\
\hline sICAM-1 (ng ml-1) & $163.4 \pm 28.3$ & $182.9 \pm 34.7 *$ & $278.2 \pm 35.6^{*} 3$ & $301.9 \pm 44.8^{\S, \wedge, \$}$ \\
\hline IL-6 (pg mI $\left.{ }^{-1}\right)$ & $1.9 \pm 0.8$ & $2.8 \pm 1.3^{*}$ & $3.3 \pm 1.2^{\S}$ & $4.9 \pm 2.0^{\wedge, \$, £}$ \\
\hline Hs-CRP $\left(\mathrm{mgl}^{-1}\right)$ & $1.2 \pm 0.3$ & $2.1 \pm 1.0 *$ & $2.4 \pm 1.2^{*}$ & $3.9 \pm 1.9 \S, \wedge, \$$ \\
\hline
\end{tabular}

Abbreviations: BG, blood glucose; Hs-CRP, high-sensitivity C reactive protein; IL-6, interleukin6; sICAM-1, soluble intercellular adhesion molecule- $1 ; \mathrm{Tg}$, triglycerides. 6; sICAM-1, soluble inter
Data are means \pm s.d.

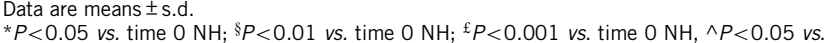
time $0 \mathrm{DH} ;{ }^{\circ} P<0.05$ vs. time $6 \mathrm{NH} ;{ }^{\$} P<0.01$ vs. time $6 \mathrm{NH}$.
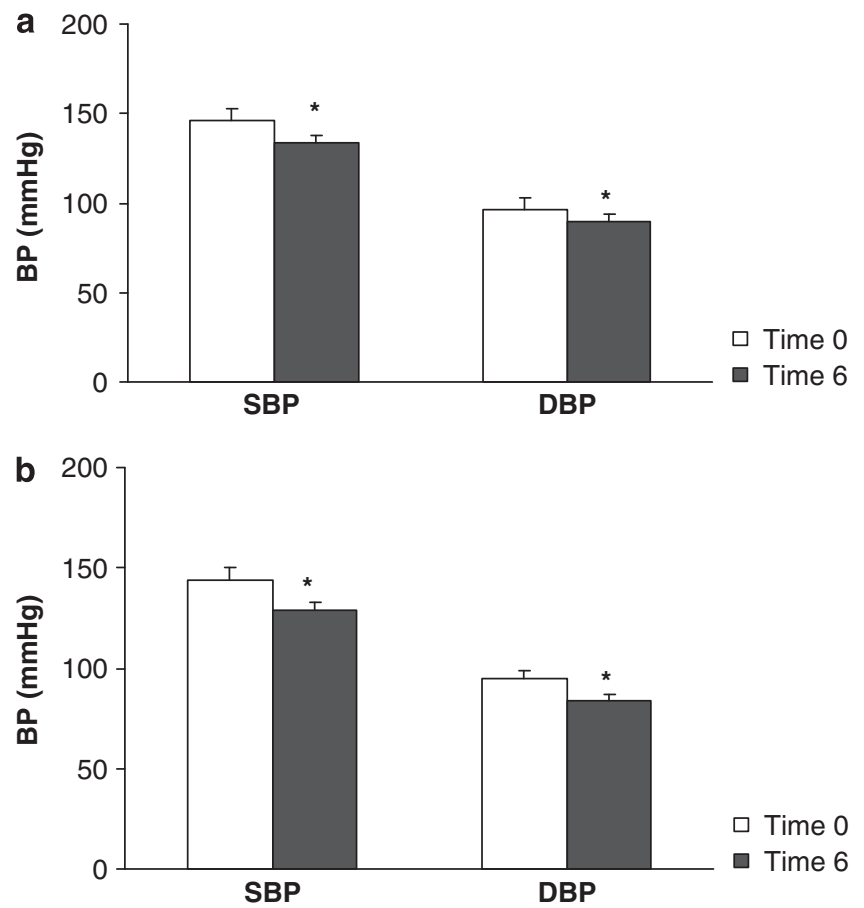

Figure $1 \mathrm{SBP}$ and DBP after 6-month candesartan therapy in nondiabetic (NH) (a) and diabetic (DH) (b) hypertensive patients. (a) Data are means \pm standard deviation. ${ }^{*} P<0.001$ vs. time $0 \mathrm{NH}$. (b) Data are means \pm s.d. ${ }^{*} P<0.001$ vs. time $0 \mathrm{DH}$. $\mathrm{NH}$, nondiabetic; $\mathrm{DH}$, diabetic; $\mathrm{BP}$, blood pressure; $\mathrm{SBP}$, systolic blood pressure; $\mathrm{DBP}$, diastolic blood pressure.

\section{Study sample after 6 months of candesartan therapy}

After 6 months of candesartan therapy, there was a significant decrease of sICAM-1, IL-6 and Hs-CRP values compared to baseline in both groups, whereas $\mathrm{BG}$ and $\mathrm{Tg}$ did not change. Comparing the two groups, BG, Tg, sICAM-1, IL-6 and Hs-CRP values obtained after 6 months of candesartan therapy were significantly higher in DH group compared to the values obtained at baseline and after 6 months of candesartan therapy in $\mathrm{NH}$ group (Table 2). Regarding the blood pressure profile, there was a comparable significant decrease of SBP and DBP values in both groups after 6 months of candesartan therapy compared to baseline (Figure 1).

\section{Study sample after the second OFL}

After OFL, there was no variation of BG, Tg or sICAM-1, whereas there was an increase of IL- 6 and Hs-CRP at time 6 in both groups compared to time 0 . 
Table 4 Time 0 and after $6 \mathrm{~h}$ during OFL after 6-month candesartan therapy in $\mathrm{NH}$ and $\mathrm{DH}$ patients

\begin{tabular}{|c|c|c|c|c|}
\hline & Time $\mathrm{Oh} \mathrm{NH}$ & Time $6 \mathrm{~h} \mathrm{NH}$ & Time $\mathrm{Oh} \mathrm{DH}$ & Time $6 h \mathrm{DH}$ \\
\hline BG (mg per $100 \mathrm{ml}$ ) & $87.9 \pm 6.4$ & $88.5 \pm 6.6$ & $131.3 \pm 9.7^{*, \circ}$ & $135.1 \pm 9.9^{*, \circ}$ \\
\hline $\operatorname{Tg}(\mathrm{mg}$ per $100 \mathrm{ml})$ & $87.8 \pm 19.8$ & $112.6 \pm 23.5$ & $130.4 \pm 33.5^{*}$ & $143.4 \pm 38.4^{*, \$}$ \\
\hline sICAM-1 (ng ml $\left.{ }^{-1}\right)$ & $139.5 \pm 20.1$ & $151.2 \pm 23.7$ & $231.8 \pm 30.8^{*}$ & $246.3 \pm 32.1^{\$ \$}$ \\
\hline IL-6 $\left(\mathrm{pg} \mathrm{ml}^{-1}\right)$ & $1.3 \pm 0.5$ & $1.7 \pm 0.7$ * & $2.2 \pm 1.1^{\S}$ & $3.0 \pm 1.2^{\wedge, \$, E}$ \\
\hline $\mathrm{Hs}-\mathrm{CRP}(\mathrm{mg} \mathrm{|-1})$ & $0.8 \pm 0.2$ & $1.3 \pm 0.5^{*}$ & $1.8 \pm 0.9 \$$ & $2.6 \pm 1.3^{\S, \wedge, \$}$ \\
\hline
\end{tabular}

Abbreviations: BG, blood glucose; Hs-CRP, high-sensitivity C reactive protein; IL-6, interleukin6; sICAM-1, soluble intercellular adhesion molecule-1; Tg, triglycerides. Data are means \pm s.d.

${ }^{\star} P<0.05$ vs. time $0 \mathrm{NH} ;{ }^{\S} P<0.01$ vs. time $0 \mathrm{NH} ;{ }^{£} P<0.001$ vs. time $0 \mathrm{NH} ; \wedge P<0.05$ vs. time $0 \mathrm{DH} ;{ }^{\circ} P<0.05$ vs. time $6 \mathrm{NH} ;{ }^{\$} P<0.01$ vs. time $6 \mathrm{NH}$.

\section{Table 5 Parameters AUC in the study}

\begin{tabular}{|c|c|c|}
\hline & NH & $D H$ \\
\hline \multicolumn{3}{|l|}{ At the baseline } \\
\hline BG AUC (mg per $100 \mathrm{ml} \times 12 \mathrm{~h}$ ) & $51436.27 \pm 3974.72$ & $93274.65 \pm 5893.14$ \\
\hline Tg AUC (mg per $100 \mathrm{ml} \times 12 \mathrm{~h}$ ) & $47486.92 \pm 21651.49$ & $76785.28 \pm 37485.62$ \\
\hline sICAM-1 AUC (ng ml-1×12h) & $101232.36 \pm 5176.69$ & $142799.82 \pm 7632.67$ \\
\hline IL-6 AUC (pg ml-1 $\times 12 \mathrm{~h})$ & $1398.67 \pm 413.95$ & $2764.46 \pm 784.62$ \\
\hline Hs-CRP AUC (mg I-1 $\times 12 \mathrm{~h})$ & $974.57 \pm 392.73$ & $1638.73 \pm 542.38$ \\
\hline \multicolumn{3}{|l|}{ After 6 months } \\
\hline BG AUC (mg per $100 \mathrm{ml} \times 12 \mathrm{~h}$ ) & $37248.32 \pm 2548.13$ & $69337.26 \pm 4210.42$ \\
\hline Tg AUC (mg per $100 \mathrm{ml} \times 12 \mathrm{~h}$ ) & $31689.522 \pm 12358.11$ & $58169.36 \pm 29552.33$ \\
\hline sICAM-1 AUC (ng ml $\left.{ }^{-1} \times 12 \mathrm{~h}\right)$ & $68431.58 \pm 3297.36$ & $119238.29 \pm 6364.18$ \\
\hline IL-6 AUC (pg ml $\left.{ }^{-1} \times 12 \mathrm{~h}\right)$ & $924.74 \pm 279.31$ & $1877.82 \pm 551.99$ \\
\hline Hs-CRP AUC (mg I-1 × $12 \mathrm{~h})$ & $536.18 \pm 215.68$ & $1132.68 \pm 478.23$ \\
\hline
\end{tabular}

Abbreviations: BG, blood glucose; DH, diabetic hypertensive patients; Hs-CRP, high-sensitivity C reactive protein; IL-6, interleukin-6; $\mathrm{NH}$, nondiabetic hypertensive patients; sICAM-1, soluble intercellular adhesion molecule-1; Tg, triglycerides.

Data are means \pm s.d.

Comparing the two groups, BG value was significantly higher in $\mathrm{DH}$ group at time 0 compared to the value obtained in $\mathrm{NH}$ group at time 0 and 6 . Furthermore, BG value was significantly higher in DH group at time 6 compared to the value obtained in $\mathrm{NH}$ group at time 0 and 6. Tg and sICAM-1 values were significantly higher in $\mathrm{DH}$ group at time 0 than in $\mathrm{NH}$ group at the same time. Furthermore, $\mathrm{Tg}$ and sICAM-1 values were significantly higher in $\mathrm{DH}$ group at time 6 compared to the values in NH group at time 0 and 6 . IL- 6 value was significantly higher in $\mathrm{DH}$ group at time 0 than the value obtained in $\mathrm{NH}$ group at the same time. Furthermore, IL- 6 value was significantly higher in DH group at time 6 than the value obtained in NH group at time 0 and 6 . Hs-CRP value was significantly higher in $\mathrm{DH}$ group at time 0 than the value observed in $\mathrm{NH}$ group at time 0 and 6; furthermore, Hs-CRP value was significantly higher in DH group at time 6 than the value obtained in $\mathrm{NH}$ group at time 0 and 6 (Tables 4 and 5).

\section{DISCUSSION}

Postprandial hypertriglyceridemia has been suggested to be a strong risk factor for cardiovascular disease, independently from the fasting plasma lipid level. ${ }^{23}$ In the large Copenhagen City Heart Study cohort, followed up for 26 years, the adjusted risk for myocardial infarction, ischemic heart disease and all-cause mortality were nearly 1.5 for each $1 \mathrm{mmoll}^{-1}$ increase in nonfasting triglyceridemia. ${ }^{24}$

In fact, normolipidemic patients affected by coronary artery disease appear to have a slowed postprandial lipid clearance than normolipidemic healthy subjects. ${ }^{25}$ Moreover, the postprandial hyperlipidemia is linked to an acute endothelial dysfunction on moderately dyslipidemic patients ${ }^{26}$ and the slower is the postload Tg clearance, the speeder the coronary atherosclerosis progression. ${ }^{27}$

In our study, we have evaluated the effect of treatment with candesartan, an angiotensin receptor blocker with weak peroxisome proliferator-actived receptor- $\alpha$ agonist activity, on the OFL-induced inflammation in type 2 diabetic and $\mathrm{NH}$ patients. The most adequate way to experimentally reproduce the postprandial lipemia condition appears to be the administration of a standardized OFL to fasting patients. ${ }^{28}$ This model has been widely applied in relatively small sample of subjects to study the postprandial lipemia effect on inflammatory parameters, ${ }^{29,30}$ circulating markers of endothelial dysfunction $^{31,32}$ and prothrombotic variables. ${ }^{33,34}$

So, we observed that 6 -month treatment is associated to a significant improvement of basal level of sICAM-1 (-17.3\%), IL-6 $(-31.6 \%)$ and Hs-CRP $(-33.3 \%)$ in nondiabetics, whereas in BG $(-3.7 \%)$, Tg $(-11.2 \%)$, sICAM-1 (-16.5\%), IL-6 (-36.6\%) and HsCRP $(-25.0 \%)$ in diabetics. These data are in line with what already observed by other research groups patients affected by hypertension ${ }^{35}$ or chronic heart failure. ${ }^{36}$ Before the treatment with candesartan, the OFL determined a significantly lower increase in $\mathrm{Tg}(+17.7 \mathrm{vs}$. $+50.5 \%)$ and Hs-CRP $(+62.5$ vs. $+75.0 \%)$ in diabetics than in nondiabetic patients. Six months of treatment with candesartan prevented the OFL-related changes in Tg and sICAM-1 level in non-diabetic patients, whereas it was associated to a reduced increase in IL-6 $(+28.6$ vs. $+47.4 \%)$ and Hs-CRP $(+62.5$ vs. $+75.0 \%)$. In diabetics, the candesartan treatment was associated to a reduced OFL-related increase in $\mathrm{Tg}(+10.0$ vs. $+17.7 \%)$, sICAM-1 $(+6.5$ vs. $+8.5 \%)$ and IL-6 (+36.4 vs. $+48.5 \%)$ level. From this observation, we could argue that the anti-inflammatory effect of candesartan is somewhat higher in non-diabetic patients, so supporting the hypothesis that the antiinflammatory activity of this drug is only partly related to its weak peroxisome proliferator-actived receptor- $\alpha$ activity, but probably to other independent characteristics of the molecule. ${ }^{37}$ Some of the candesartan anti-inflammatory effects mediated by suppression of nuclear factor- $\kappa \mathrm{B}$ activation and chemokine expression appear to be dose dependent ${ }^{38}$ and the strong effect that we observed in our study could be related to the use of the maximal consented dose of this drug.

Our study has some limitations. The first one is the relatively small sample of the studied patients that reduces the ability to infer the results. Another one is that we did dose a limited number of inflammation biomarkers, concentrating our attention to the most studied ones. However, at the best of our knowledge, this is the first study investigating the effect of an angiotensin II receptor antagonist on the inflammation associated to postprandial hyperlipidemia.

In conclusion, in our study carried out on type 2 diabetic and $\mathrm{NH}$ patients we observed that candesartan treatment attenuated the inflammatory answer in both group of patients, even if more efficiently in nondiabetic ones.

\section{ACKNOWLEDGEMENTS}

The publication of this article was sponsored by Takeda (Italy). The sponsors did not have any role in funding, designing or conducting the study. They had no role in drafting, writing or reviewing this article. The authors take full responsibility for the views expressed in this article that may not be shared by the sponsors.

1 Insull Jr W. The pathology of atherosclerosis: plaque development and plaque responses to medical treatment. Am J Med 2009; 122(Suppl 1): S3-S14. 
2 Addison S, Stas S, Hayden MR, Sowers JR. Insulin resistance and blood pressure. Curr Hypertens Rep 2008; 10: 319-325.

3 Hirono Y, Yoshimoto T, Suzuki N, Sugiyama T, Sakurada M, Takai S, Kobayashi N, Shichiri M, Hirata Y. Angiotensin II receptor type 1-mediated vascular oxidative stress and proinflammatory gene expression in aldosterone-induced hypertension: the possible role of local renin-angiotensin system. Endocrinology 2007; 148: 1688-1696.

4 Ferder L, Inserra F, Martínez-Maldonado M. Inflammation and the metabolic syndrome: role of angiotensin II and oxidative stress. Curr Hypertens Rep 2006; 8: 191-198.

5 Kyvelou SM, Vyssoulis GP, Karpanou EA, Adamopoulos DN, Gialernios TP, Pietri PG, Cokkinos DV, Stefanadis $\mathrm{Cl}$. Beneficial effects of angiotensin II type 1 receptor blocker antihypertensive treatment on inflammation indices: the effect of smoking. J Clin Hypertens (Greenwich) 2007; 9: 21-27.

6 Yano Y, Hoshide S, Ishikawa J, Noguchi C, Tukui D, Takanori H, Tada M, Kanemaru Y, Yano A, Ishikawa S, Shimada K, Kario K. The differential effects of angiotensin II type 1 receptor blockers on microalbuminuria in relation to low-grade inflammation in metabolic hypertensive patients. Am J Hypertens 2007; 20: 565-572.

7 Park H, Hasegawa G, Obayashi H, Fujinami A, Ohta M, Hara H, Adachi T, Tamaki S, Nakajima Y, Kimura F, Ogata M, Fukui M, Yoshikawa T, Nakamura N. Relationship between insulin resistance and inflammatory markers and anti-inflammatory effect of losartan in patients with type 2 diabetes and hypertension. Clin Chim Acta 2006; 374: 129-134.

8 Voors AA. Vascular benefits of angiotensin receptor blockers. Expert Opin Investig Drugs 2007; 16: 987-997.

9 Tanaka T, Ordovas JM, Delgado-Lista J, Perez-Jimenez F, Marin C, Perez-Martinez P, Gomez P, Lopez-Miranda J. Peroxisome proliferator-activated receptor alpha polymorphisms and postprandial lipemia in healthy men. J Lipid Res 2007; 48: 1402-1408.

10 American Diabetes Association. Screening for diabetes (Position Statement). Diabetes Care 2001; 24 (Suppl): S21-S24.

11 Matthews DR, Hosker JP, Rudenski AS, Naylor BA, Treacher DF, Turner RC. Homeostasis model assessment: Insulin resistance and beta-cell function from fasting plasma glucose and insulin concentrations in man. Diabetologia 1985; 28: 412-419.

12 European Diabetes Policy Group. A desktop guide to type 2 diabetes mellitus. Diab Med 1999; 16: 716-730.

13 Heding LG. Determination of total serum insulin (IRI) in insulin-treated diabetic patients. Diabetologia 1972; 8: 260-266.

14 Klose S, Borner K. Enzymatische Bestimmung des Gesamtcholesterins mit dem Greiner selective analyzer (GSA II). J Clin Chem Clin Biochem 1978; 15: 121-130.

15 Wahlefeld AW. Triglycerides determination after enzymatic hydrolysis. In Bermeyer HU (eds), Methods of Enzymatic Analysis. 2nd English edn. Academic Press: New York, 1974, pp. 18-31.

16 Havel RJ, Edr HA, Bragdon JH. The distribution and chemical composition of ultracentrifugally separated lipoproteins in human serum. J Clin Invest 1955; 34: 1345-1353.

17 Friedewald WT, Levy RI, Fredrickson DS. Estimation of the concentration of low density lipoprotein in plasma, without use of the preparative ultracentrifuge. Clin Chem 1972; 18: 499-502.

18 Song M, Kellum JA. Interleukin-6. Crit Care Med 2005; 33: S463-S465.

19 Rifai N, Tracy RP, Ridker PM. Clinical efficacy of an automated high-sensitivity C-reactive protein assay. Clin Chem 1999; 45: 2136-2141.

20 Witkowska AM, Borawska MH. Soluble intercellular adhesion molecule-1 (sICAM-1): an overview. Eur Cytokine Netw 2004; 15: 91-98.

21 Winer BJ. Statistical Principles in Experimental Design, 2nd edn. McGraw-Hill: New York, 1971.
22 Matthews JNS, Altman DG, Campbell MJ, Royton P. Analysis of serial measurements in medical research. BMJ 1990; 300: 230-235.

23 McBride PE. Triglycerides and risk for coronary heart disease. JAMA 2007; 298 . 336-338.

24 Nordestgaard BG, Benn M, Schnohr P, Tybjaerg-Hansen A. Nonfasting triglycerides and risk of myocardial infarction, ischemic heart disease, and death in men and women. JAMA 2007; 298: 299-308.

25 Groot PH, van Stiphout WA, Krauss XH, Jansen $H$, van Tol A, van Ramshorst E, Chin-On S, Hofman A, Cresswell SR, Havekes L. Postprandial lipoprotein metabolism in normolipidemic men with and without coronary artery disease. Arterioscler Thromb 1991; 11: 653-662.

26 Maggi FM, Raselli S, Grigore L, Redaelli L, Fantappiè S, Catapano AL. Lipoprotein remnants and endothelial dysfunction in the postprandial phase. J Clin Endocrinol Metab 2004; 89: 2946-2950

27 Karpe F, Steiner G, Uffelman K, Olivecrona T, Hamsten A. Postprandial lipoproteins and progression of coronary atherosclerosis. Atherosclerosis 1994; 106: 83-97.

28 Parks EJ. Recent findings in the study of postprandial lipemia. Curr Atheroscler Rep 2001; 3: 462-470.

29 Halkes CJ, van Dijk H, de Jaegere PP, Plokker HW, van Der Helm Y, Erkelens DW, Castro Cabezas M. Postprandial increase of complement component 3 in normolipidemic patients with coronary artery disease: effects of expanded-dose simvastatin. Arterioscler Thromb Vasc Biol 2001; 21: 1526-1530.

30 Alipour A, Elte JW, van Zaanen HC, Rietveld AP, Cabezas MC. Postprandial inflammation and endothelial dysfuction. Biochem Soc Trans 2007; 35(Part 3): 466-469.

31 Norata GD, Grigore L, Raselli S, Redaelli L, Hamsten A, Maggi F, Eriksson P, Catapano AL. Post-prandial endothelial dysfunction in hypertriglyceridemic subjects: molecular mechanisms and gene expression studies. Atherosclerosis 2007; 193: 321-327.

32 Tsai WC, Li YH, Lin CC, Chao TH, Chen JH. Effects of oxidative stress on endothelial function after a high-fat meal. Clin Sci 2004; 106: 315-319.

33 Jastrzebska M, Przybycień K, Chelstowski K, Torbus-Lisiecka B, Kornacewicz-Jach Z, Naruszewicz M. Increased levels of factor VII, fibrinogen and activity of plasminogen activator inhibitor during postprandial triglyceridemia in patients with ischemic heart disease confirmed by angiography. Nutr Metab Cardiovasc Dis 1999; 9: 33-40.

34 Silveira A, Karpe F, Blombäck M, Steiner G, Walldius G, Hamsten A. Activation of coagulation factor VII during alimentary lipemia. Arterioscler Thromb 1994; 14: 60-69.

35 Koh KK, Quon MJ, Han SH, Chung WJ, Lee Y, Shin EK. Anti-inflammatory and metabolic effects of candesartan in hypertensive patients. Int J Cardiol 2006; 108: 96-100.

36 Tsutamoto T, Wada A, Maeda K, Mabuchi N, Hayashi M, Tsutsui T, Ohnishi M, Sawaki M, Fujii M, Matsumoto T, Kinoshita M. Angiotensin II type 1 receptor antagonist decreases plasma levels of tumor necrosis factor alpha, interleukin- 6 and soluble adhesion molecules in patients with chronic heart failure. J Am Coll Cardiol 2000; 35: 714-721.

37 Chen S, Ge Y, Si J, Rifai A, Dworkin LD, Gong R. Candesartan suppresses chronic renal inflammation by a novel antioxidant action independent of AT1R blockade. Kidney Int 2008; 74: 1128-1138.

38 Yu C, Gong R, Rifai A, Tolbert EM, Dworkin LD. Long-term, high-dosage candesartan suppresses inflammation and injury in chronic kidney disease: nonhemodynamic renal protection. J Am Soc Nephrol 2007; 18: 750-759. 